\title{
Colon Classification and Nuovo Soggettario: The Case of the Library of the Natural History Museum of Udine, Italy
}

\author{
Carlo Bianchini \\ Facoltà di Musicologia, Università degli Studi di Pavia, \\ Corso Garibaldi, Cremona, Italy, 178-I-26100, \\ <carlo.bianchini@unipv.it>
}

Carlo Bianchini is a Researcher in LIS at the Facoltà di Musicologia of the University of Pavia. He was Assistant Librarian at the Accademia dei Concordi, Rovigo (1991-1998), then Head Librarian of the Natural History Museum (2000-2010), Udine. He is a member of the editorial board of JLis.it. He was a member of the Cataloguing Commission of the Italian Library Association (2005-2011) and of the editorial board of Bibliotheca. Rivista di studi bibliografici (2003-2007). He received his M.L.S. and Ph.D. in LIS from the University of Udine. His main research interests deal with knowledge organization, cataloguing theory, and classification (mainly CC and Ranganathan's works).

Bianchini, Carlo. Colon Classification and Nuovo Soggettario: The Case of the Library of the Natural History Museum of Udine, Italy. Knowledge Organization, 39(1), 23-28. 10 references.

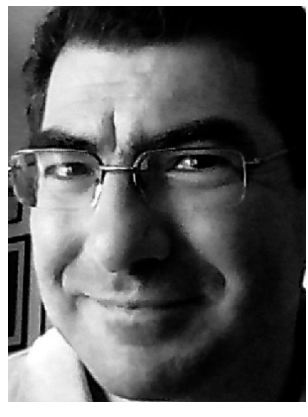

ABSTRACT: The paper presents the results of five years of application of Colon Classification (CC), 6. ed., in the Library of the Natural History Museum of Udine, Italy. Research confirms that CC still presents those positive characteristics that gave fame to it. The paper compares CC and the Dewey Decimal Classification by means of a special indicator (resolution power), and it shows how the use of CC could greatly help Italian cataloguers using Nuovo Soggettario, the new thesaurus developed and used at the Biblioteca Centrale Nazionale di Firenze, where Bibliografia Nazionale Italiana is also produced. Use of CC6 during these five years demonstrated that a faceted classification offers great advantages in organizing documents in a modern library, even if $C C$ is surely in need of updating and revision.

Received 22 July 2011; Accepted 22 July 2011

\subsection{Introduction}

Colon Classification (CC) has a very limited circulation both in India and in the rest of the world, despite being the very first analytical-synthetic classification and being the result of a revolutionary approach to bibliographic classification. Nevertheless, Ranganathan's theoretical efforts in systematizing bibliographic classification and his original intuitions have surely played a relevant role in influencing any later indexing system, in particular analytical-synthetic approach, facet analysis, citation order, categories, and treatment of composed terms. Other fundamental components of analytical-synthetic classifications can also be recognized easily within the Nuovo Soggettario
(Biblioteca nazionale centrale di Firenze 2006) - the new general Italian thesaurus developed by Biblioteca Nazionale Centrale di Firenze, now spreading all over Italy - derived first from the studies of the Classification Research Group (CRG) and then from the works of GRIS - Gruppo di ricerca sullindicizzazione per soggetto dell'Associazione Italiana Biblioteche (AIB Subject indexing Research Group).

During 2005, a new classification was needed at the library of the Natural History Museum of Udine, Italy, and Colon Classification was adopted. This paper presents the results of the application of Colon Classification, a comparison between Colon Classification and Dewey Decimal Classification based on a special indicator (resolution power), the recording of classifi- 
cation authority data in ILS, the choices and the changes to schedules applying Colon Classification, 6th ed., and the reasons why the adoption of Colon Classification would be particularly useful in Italian libraries using the new Italian thesaurus (Nuovo Soggettario).

\subsection{Use of Colon Classification at the library of the Natural History Museum, Udine}

Relationships between the Italian Nuovo Soggettario and Ranganathan's faceted approach are described in a work of GRIS of AIB-a research group on subject indexing of the Italian Library Association (Associazione Italiana Biblioteche, Gruppo di ricerca sull'indicizzazione per soggetto 1996, VII):

In the last half century, research and experimentation created and defined a system of concepts and methods that today we use in our everyday work of analysis and indexing, of authority control and normalization, of teaching: concepts like facets, categories, roles, and functional distinction between semantic [...] and syntactical [...] relationships, citation order, principles for compound subjects, distinction between indexing and access vocabularies. All these results were derived from Ranganathan's deep theoretical foundation and, later, mainly from the English Classification Research Group, with Coates, Farradane, and Derek Austin.

-and also in the manual of Nuovo soggettario (Biblioteca nazionale centrale di Firenze 2006, 26) and in Cheti (2004). Colon Classification and Nuovo Soggettario share deep affinities, both in the process of subject analysis and of translation of concepts in their specific languages; these affinities deserve further studies and consideration, as in the future, they could play an important role in contributing to the simultaneous spreading of Nuovo Soggettario and Colon Classification in the Italian context.

The great affinities between Nuovo Soggettario and Colon Classification were just one of the reasons for adopting Colon Classification in the specialized library of the Natural History Museum of Udine, Italy (in fact Nuovo Soggettario was not yet published in 2005). Other reasons were inadequacy of the shelving system adopted up to 2005 that had caused the increasing piling up of documents waiting to be shelved and inadequacy of the Dewey Decimal Classification $(D D C), 21$ st ed., used in the library since 2000 , in expressing class numbers coextensive to the specialized subjects of the library; in fact, $D D C$ did not supply an effective service to the users, and it was totally refused by a large number of the curators of the Museum, also due to past negative experiences (unfortunately based on $D D C, 11$ th abridged ed.).

The solution seemed to be sought among faceted classification systems, and the final choice of the Colon Classification was supported by two further reasons: a) it was the first and most prestigious faceted classification, and b) it had a very low cost, as it is largely cheaper than any other classification. In fact, up to now, Colon Classification is the cheapest general classification (with a cost of US\$10-15, shipping included) available to any kind of library. Further, in 2005, Bliss Classification, 2nd ed., had not published the schedules of DG/DY Earth sciences, E/GQ Biological sciences nor GR/GZ Applied biological sciences: agriculture and ecology, i.e., the classes of main interest for the library of the Natural History Museum (see http:// www.blissclassification.org.uk/bcsched.shtml); in the meantime, the Universal Decimal Classification (UDC) did not seem equivalent to Colon Classification as to shortness of notation. The choice of the sixth edition instead of the seventh was due not only to greater availability, but also to critical reviews of the last edition (Satija 1990).

Before introducing Colon Classification, the library of the Natural History Museum catalogued its bibliographic resources following the main national and international standards, such as RICA (Istituto centrale per il catalogo unico delle biblioteche italiane e per le informazioni bibliografiche 1979) and ISBD, Soggettario di Firenze (Biblioteca Nazionale Centrale di Firenze 1956), and Dewey Decimal Classification, 21st ed. All of the accesses provided in the catalogue were to be continued, as they were indispensable to grant the quality standard of the services offered to users; so the experimental phase required supplementary work to provide access by Colon Classification and to shelve resources by a new kind of book number.

Fortunately, double classification of resources allowed us to reach two further objectives: 1) application of facet analysis of documents-explicitly required by Colon Classification - also to subject indexing work by Soggettario di Firenze (Biblioteca Nazionale Centrale di Firenze 1956) and DDC; and 2) a direct and continuous comparison between Colon Classification and DDC. Facet analysis is an unavoidable and fundamental feature of Colon Classification; so, the first positive impact of using Colon Classification was its specific educational value in training the cata- 
loguers in the use of facet analysis, based on the seven steps described by Ranganathan to assure accuracy in classified indexing (Ranganathan 1960, part 1, 7). Facet analysis resulted to be very useful and propaedeutic for the study and use of the Nuovo soggettario.

Contextual use of Colon Classification, Soggettario di Firenze (Biblioteca Nazionale Centrale di Firenze 1956), and DDC allowed us to note that Colon Classification was often able to express detailed subjects that Soggettario di Firenze or DDC were able to represent only partially-from a semantic or syntactic point of view. In the experimental phase, features that gave fame to Colon Classification were practically verified: flexibility, adaptability, high level of intension (or connotation), and larger coextension between class number and subjects. Other positive characteristic are mnemonic quality and userfriendliness of the classification system, thanks to general schedules (common isolates, time isolates, space isolates, and language isolates) applicable by definition to any main or canonical class of the classification. In particular, space and time isolates are always applicable-but for special stipulations given at the beginning of the schedules for each main or canonical class-following the citation formula PMEST (Personality, Matter, Energy, Space and Time): this is a relevant difference with $D D C$, in which class number faceting is possible only if explicitly allowed for.

For example in DDC22, to apply subdivision 012 [Zoological] Classification to number 594.32 Prosobranchia, one needs to follow note "*Add as instructed under 592-599" (vol. 2, p. 1191); there (p. 1186), one finds a second link to: "01-08 Standard subdivisions. Notation from Table 1 as modified under 590.1-590.8, e.g., collections of living animals 073"; then, at p. 1180, under 590.1-.6 Standard subdivisions, one finds the third link "Notation from Table 1 as modified under 578.01-578.06"; finally, after a further step, the number to be applied is found at $\mathrm{p}$. 1139: 012 Classification. But it is necessary to go backwards to the starting point to be sure about the number and the position of facet indicator $\mathrm{O}$. In $\mathrm{Co}$ lon Classification (p. 2-51), the subdivision of the example (11 Nomenclature, Classification) is one of the characteristics (facet E) of main class G Biology, applicable without limits (but with some additions) also and directly to main classes I Botany and K Zoology and their subdivisions.

Five kinds of common isolates systematically applicable everywhere surely make the process of memorization easier to the cataloguer. Using $C C$, the cataloguer very easily gains a systematic approach in discovering and supplying any aspect of the thema not explicitly stated by the resource (especially space and time facets).

\subsection{Comparing classification systems by resolution power}

To compare indexing capabilities of Colon Classification and Dewey Decimal Classification, the resolution power of classification system was identified and used as an indicator; resolution refers to the capability of a classification to distinguish each possible subject from other similar, but not identical, subjects. For the purposes of this research, the value of the resolution power $(\mathrm{R})$ of a classification (CL) was defined as the ratio between the total amount of class numbers $(\mathrm{C})$ used to classify a set of resources (S) and the total amount of the resources $(\operatorname{Tr})$ in that set:

$$
R(C L)=\frac{C(S)}{\operatorname{Tr}(S)}
$$

The indicator allows objective comparison of the value of different indexing systems only if it is applied 1) to an extremely highly homogeneous, if not identical, set of resources; and 2) in a very specific and limited indexing context. Both conditions were satisfied by the library of the Natural History Museum of Udine.

From January 2006 to May 2010, more than 1.500 Colon class numbers were created, to classify more than 2.200 resources. The resolution power of CC, represented by $\mathrm{R}(C C)$, in this specific case, is the result of the following formula:

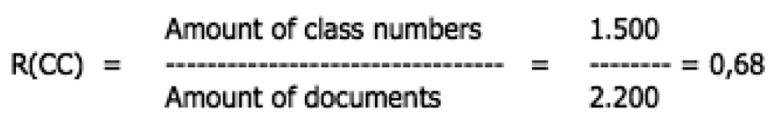

From January 2000 to May 2010, a larger period of time, 3627 DDC class numbers were recorded to classify 10.500 documents (including 2.200 documents classified also by $C C$ ), so that the resolution power of $D D C$, represented by $\mathrm{R}(D D C)$, in this specific case, can be calculated as follow:

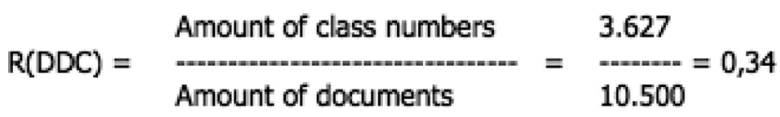

It turns out that $\mathrm{R}(C C)$ is double $\mathrm{R}(D D C)$. Even if these data are based upon just one case, and they cannot assume an absolute value, because many other analyses should be developed on other disciplines and 
collections, they highlight a surely higher resolution power of the CC. In this case, resolution power is double in CC; but it must be underlined that the ratio is calculated just for class numbers of both classifications, while resolution power of book numbersexplicitly provided in $C C$ but not in $D D C$ - is ignored. Nevertheless it could probably be taken into account to calculate effective resolution power of each classification, as well.

\subsection{The Classification authority file}

ILS used in the library of Natural History Museum of Udine allows the management of more classification authority files; a specific authority file for the Colon Classification was created. Unfortunately, the ILS does not allow any link among equivalent (USE, UF), associated (RT) or hierarchical (BT and NT) terms. This was a relevant negative aspect of the research that should be deepened on this point.

Metadata in the Colon authority record were very limited, as shown in Example no. 1. Colon authority records were composed of four fields: "Class number," "Kind of Classification," "Description," and "Notes." The first field contains the notation of the class number; the second one contains an acronym for the classification (e.g., "CDD" for DDC and "CL1" for CC); the third field was for the caption, and the fourth field contains notes (note of use, note of context, etc.).

While ILS provided indexing of the field "Class number," but not of the field "Description," the possibility of searching by "caption" any previous record containing the same facet was a very important feature to grant consistency to authority records. For the nature of notation, this would have been possible only by means of the caption and not of the class number representing each facet. For these reasons, both the class numbers and the captions were recorded in the field "class number," after five blanks (represented by symbol \#). Data were recorded as in example no. 1 :

Example no. 1

\begin{tabular}{|l|l|}
\hline Class number: & $\begin{array}{l}\text { K88:2.521\#\#\#\#\#[Arachnida: } \\
\text { Morphology = Anatomy. } \\
\text { Piemonte] }\end{array}$ \\
\hline Kind of Classif.: & CL1 \\
\hline Description: & $\begin{array}{l}\text { Arachnida: Morphology }= \\
\text { Anatomy. Piemonte }\end{array}$ \\
\hline Notes: & --- \\
\hline
\end{tabular}

The capability to search also by caption was really very useful, both because it made the process of memorization of $C C$ schedules easier, and because it offered a first simple tool of authority work. It must be noted that an actual authority control could have been possible only using a specifically-designed tool, in which each isolate could get its own record and class numbers are created by juxtaposition of isolates, on the basis of their syntactical and semantic values and of the citation order.

To avoid inconsistencies in the captions, the original English form of the facet name was adopted, but for Italian geographical names. In some cases, if the caption of the Colon Classification was not completely satisfying for searching purposes, a variant form of the facet name was included in the description as equivalent, after the equals sign (as in the above example for "Morphology" and "Anatomy").

\subsection{Choices and changes applying Colon Classification}

Applying Colon Classification, general choices were required by the system itself, but a few changes were also necessary to update the classification scheme or to adapt it to users' needs.

Some choices were required or allowed by Colon Classification; in these cases, all the provisions of the scheme were applied. In other cases, some changes were intended for simplifying the construction of class numbers, for making class numbers more understandable, or for updating schedules. These last changes were decided and applied absolutely free, as Colon Classification lacks the institutional support that benefits other modern systems such as DDC, $U D C$, and Library of Congress Classification (Satija 1997). Ranganathan's suggestions in his Prolegomena to library classification (1967) and in the manual of Colon Classification (Ranganathan 1960) and, where interoperable, solutions proposed in the 7 th edition of Colon Classification were taken into account in deciding upon any change to the schedules.

The first general choice was the use of Italian as favoured language, that is by definition "the language in which the majority of the books of the library are found written" (Ranganathan 1960, part 1, 10) and it is usually, but not necessarily, also the language of the country of the library (Ranganathan 1967, 508). Colon Classification suggests omitting the language facet when the document is in the favoured language, except for main class O Literature (Ranganathan 1960, part 1,11). For this reason, in the application of the 
Colon Classification, the language facet for Italian language resources was omitted in book numbers.

A second general choice concerned the facet of the year of publication in the book numbers; it must be noted that, in Colon Classification, the year of publication is a relevant and characterizing element to individualize each document on the basis of the fifth law (Library is a growing organism). Colon Classification provides two different systems of notation for the year of publication: the main one (Time Schedule given in chapter 3 of Colon Classification) allows the identification of the time facet using three digits for each year; the alternative system allows the use of just two digits for each year, but starting from 1880 on. The second option (Special chronological schedule for the Book Number) provided in the Colon Classification Manual (Ranganathan 1960, part 1,12) is very useful for relatively recent holdings. At the library of the Natural History museum, the special chronological table for modern libraries was adopted.

The first change of general relevance to the schedules was related to the notation for the language isolates to be included in the book numbers. Colon Classification allows the use of the language isolate schedules for the book number, as well. In the schedules, a three digit number is associated with each language (e.g., 111 English, 122 French and so on). While applying Colon, it was noted that this notation has two shortcomings: 1) to be useful, the meaning of these three digits must be memorized by the librarian and by the users; 2) the language isolate schedules are largely incomplete and in urgent need of revision. On the contrary, another system of notation is currently in use, largely spread in a library context, immediately understandable, including nearly the totality of world languages, and requiring exactly three digits. So, it was decided to substitute language isolate schedules in creating book numbers with the standard ISO 639-2 /B for languages. Now, the English language is represented by ENG instead of 111, the French language by FRE instead of 122, and so on.

The second change of general relevance to the schedules was related to the Space subdivision. Political subdivision of isolate 52 Italy in CC, 6th ed., was just drafted, and in the $C C$, 7 th ed., it reached a regional level, but was in need of revision.

The application of the CC in the library of the Natural History Museum needed a detailed level of geographical subdivisions (up to municipal divisions); reliability and updating were urgently needed, too. However, there were no financial or human resources available, so it was absolutely impossible to develop an ad hoc schedule. A final decision was made to adopt an adapted version of the geographical schedules of DDC. In the specific case, for political and administrative division of Italy, number -45 Italy of $D D C$ was substituted by number -52 Italy of CC. The result was that, for instance, the Friuli Venezia Giulia Region got number - 5239 in the CC (as it was -4539 in the $D D C$ ), Florence got number -52511 (as it was -45511 in the $D D C$ ), and so on. In consideration of the geographical position of Udine (NE Italy), during the use of the Colon with the special collections of the Museum, it was decided to apply the same kind of changes also for the isolates of the neighboring countries (Austria, Slovenia, and Croatia).

The high specialized collections of the Museum could be classified only with updated and revised schedules for natural sciences; in many cases, the schedules of the 6th edition were modified by taking isolates from 7 th edition or, for some animal species, from the Checklist delle specie della fauna italiana (Minelli, Ruffo, and La Posta 1993-95). Taxonomical meaning of many isolates of classes I Botany and $\mathrm{K}$ Zoology appeared very outdated, and schedules absolutely needed deep revisions in this part. Nevertheless, during the research, the value of Colon Classification in conceptual and physical organization of the documents was largely evident. In other cases, the updating of revision of the caption or the addition of a few isolates was sufficient. Main classes that required more changes were 2 Library science, G Biology and $K$ Zoology. The whole list of new isolates is omitted here for space reasons.

\subsection{Conclusion}

The use of the Colon Classification, 6th edition, during these five years demonstrated that a faceted classification offers great advantages in organizing documents in a modern library, even if CC is still in need of updating and revision. If some main classes are in need of updating or revision, this need probably depends on the application of the Colon Classification in a specialized library (as discussed for K Zoology o G Biology). With minor changes, Colon Classification could easily be used today in Italian public libraries with general collections, and this choice could greatly help with the use of the Nuovo soggettario, too.

The use of the schedules of main class $O$ Literature could also be particularly relevant for Italian public libraries. In fact, Colon Classification can assure an organization of documents of very high quality, in- 
comparably more useful than that adopted by the largest majority of Italian public libraries (based on DDC plus three digits taken from author or title). Ranganathan's Classic Device (CID) would be particularly useful in these cases (Ranganathan 1960, part 1, 59). Colon Classification still has large potentialities to be adopted and used in many Italian small libraries, and could also be adopted and used in special, research and university libraries with greater, but surely not unsustainable, effort.

\section{References}

Cheti, Alberto. 2004. Dal Dewey italiano al nuovo soggettario. Studi ed esperienze intorno a un modello di indicizzazione per soggetto. In Danesi, Daniele ed. Studi e testimonianze offerti a Luigi Crocetti. Milano: Bibliografica, pp. 549-74.

Associazione Italiana Biblioteche, Gruppo di ricerca sull'indicizzazione per soggetto. 1996. Guida all'indicizzazione per soggetto. Roma: AIB.

Biblioteca nazionale centrale di Firenze ed. 1956. Soggettario per $i$ cataloghi delle biblioteche italiane. Firenze: Stamperia Il Cenacolo.
Biblioteca nazionale centrale di Firenze. 2006. Nuovo soggettario. Guida al sistema italiano di indicizzazione per soggetto. Prototipo del thesaurus. Milano: Bibliografica.

Istituto centrale per il catalogo unico delle biblioteche italiane e per le informazioni bibliografiche. 1979. Regole italiane di catalogazione per autori. Roma: ICCU.

Minelli, Alessandro, Ruffo, Sandro, and La Posta, Sandro eds. 1993-1995. Checklist delle specie della fauna italiana. Bologna: Calderini.

Ranganathan, Shiyali Ramamrita. 1960. Colon Classification; basic classification. $6^{\text {th }}$ ed. Bangalore: Sarada Ranganathan Endowment for Library Science.

Ranganathan, Shiyali Ramamrita. 1967. Prolegomena to library classification. $3^{\text {rd }}$ ed. Bangalore: Sarada Ranganathan Endowment for Library Science.

Satija, Mohinder Partap. 1990. A critical introduction to the 7th edition (1987) of the Colon Classification. Cataloging $E$ classification quarterly 12 no. 2: 125-38.

Satija, Mohinder Partap. 1997. The revision and future of Colon Classification. Knowledge organization 24: 18-23. 